\title{
Effects of aerobic exercise on psychosocial traits among people living with HIV/AIDS in Nekemte, Ethiopia
}

\author{
Girma Tilahun ${ }^{1}$, Soumitra Mondal ${ }^{2}$, Dhamodharan Mathivanan ${ }^{2}$, \\ Mohamud Abdulkedar ${ }^{3}$ \\ ${ }^{1}$ Sport Science Department,Wollega University, Ethiopia. \\ ${ }^{2}$ Sport Science Department, Mekelle University, Ethiopia. \\ ${ }^{3}$ Immunology Department Biomedical Institute Mekelle University, Ethiopia.
}

\begin{abstract}
In the recent decades, the positive psycho-social considered as an ability of human beings which are provided appropriate studies in well-being and happiness domains. In this way, the purpose of this research was to identify the effect of twelve weeks aerobic exercise on psychosocial trait among people living with HIV/AIDS. This study was a randomized clinical controlled trial. The Study Population was from Nekemte city of people living with HIV/AIDS (PLWHIV) under antiretroviral therapy (ART). Of PLWHIV under ART two hundred fifty $(n=250)$ were volunteered and willing to participate. After inclusive and exclusive criteria applied 58 subjects were selected by simple lottery method, strata and randomly assigned in experimental and control groups. World Health Organization quality of life assessment instrument (the WHOQOL) (WHOQOL-brief 1994b) psychosocial questioner was administrated to collect the pre test and after the intervention post test data was collected with same questioner. Experimental group were participated in aerobic exercise programmed for 12 weeks. Control group were encouraged to attend ART and advised usual day to day activity. The collected data were analyzed by paired $t-$ test and independent $t$-test by using SPSS version 20 . The level of significance for all analyses was set at $\mathrm{P}<0.05$. However, after 12-weeks psychosocial trait had shown significant change $(\mathrm{P}=0.00)$ observed in exercise group where as control group insignificant $(\mathrm{p}=81$ ) and which is an effective complementary therapy to improved psychosocial trait in PLWHA. It was concluded that the three-month, supervised, and moderate aerobic exercise program, performed three times a week, can improve the psychosocial traits. Aerobic exercise has a positive effect on psychosocial trait in people
\end{abstract}

living with HIV/AIDS when it combines with ART rather than ART alone.

Keywords. Aerobic exercise, ART, HIV/AIDS, PLWHA, psychosocial.

\section{Introduction}

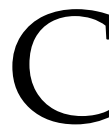

linical research and interest in health-related quality of life (HRQOL) began more than 50 years ago with the World Health Organization's definition of health as not just the absence of disease, but a state of physical, mental and social well-being (Smith et al., 2001). There are two broad categories in which quality of life (QOL) can be divided. The first uses a satisfaction model based on generic measures of well-being and life satisfaction in multiple domains, with most of them unrelated to health. The second category includes an HR-QOL and is based on measures of sickness impact (Eller, 2001). It refers to how well a person functions to his or her perception of well-being in the physical, mental and social domains of life (Fillipas et al., 2006).

People living with HIV/AIDS (PLWHA) feel uncertainty and they have to cope with the situation. Feelings of insecurity have its origin in the fear of the upcoming future and the people focus on their families and their Fob (Bhasin et al., 2000; Fairfield et al., 2001). They feel even more uncertain and are more concerned

Received: November 28, 2018 - Accepted: December 29, 2018 - Published: December 30, 2018

To cite this article: Tilahun G, Mondal S, Mathivanan D, Abdulkedar M. Effects of aerobic exercise on psychosocial traits among people living with HIV/AIDS in Nekemte, Ethiopia. Turk J Kinesiol, 2018; 4(4): 142-148.

$\triangle$ S. Mondal, e-mail: soumitramk@yahoo.co.in DOI: 10.31459/turkjkin.489089 
because of the quality of life and life expectancy as well the treatment outcome and the reaction of the society Probably there is a significant improvement in the depression subscale of the Profile of Mood States Scale (POMS) for participants in the exercise intervention group compared with the non-exercising control group (LaPerriere et al., 1990).

According to this study it is quite possible that aerobic exercise could give a beneficial outcome in psychosocial trite in adults with HIV.

\section{Methods}

\section{Study Area and Study Design}

This study was conducted in Nekemete town found in the east Wollega zone, Oromia regional state, Ethiopia. The study design was randomized controlled clinical trial. It was 12-weeks aerobic exercise training intervention of three days per week supervised aerobic exercise.

\section{Selection of Subject and Study Design}

All subjects fulfilling selection criteria were provided informed consent for participating in the research .58 volunteers of both male and female in the age range of 30-45 years old were selected to be research participants. Stratified method was used in order to homogenous of gender distribution followed by simple random method 29 participants were assigned in control and 29 in the experimental groups. Participant's gender distribution demonstrated 33 were female and 25 were male. Exercise group parcipeted on 12 weeks aerobic exercise 3 days/week for 12 months and control group carry on their Activities of daily living \&his /her occupation. The study was ranadamization clinical trial design.

\section{Selection Criteria}

The researchers used inclusion and exclusion criteria during the selection of participants.

\section{Inclusion criteria}

1) Both female and male under ART. 2) The distribution of HIV prevalence also varies by age, peaking in the 30-40 years age group compared to the other (FDRE, 2014). Because of this, the 30-40 was selected. 3) Participants who have been on first-line antiretroviral therapy was selected. 4) Willing and able to give an informed and agree to consent. 5) Free of HIV/AIDS-related chronic infections that do not allow aerobic exercise

\section{Exclusion criteria}

1) Participants with a history of central nervous system dysfunction, hemiparesis (paralysis of one side of the body). 2) Diabetic patients. 3) Participant on either as prophylaxis, such as the use of antibiotics to prevent infections or as part of $\mathrm{TB}$ treatment. 4) Pregnant and lactating women. 5) Three of risk factors those are series cardiac problem. 6) A participant who remains in the study area throughout the period of study.

\section{Administration of the Test and Collection of the Data}

Prior conduct of the study, ethical clearance was taken from Health Research and Ethical Review Committee of Mekelle University registration, No ERC0771/2016, registered under clinicaltrials.gov of registration no. NCT03009149 and permission was taken from regional laboratory. The researcher was explained all the necessary information about the study to all the participants and also educated about 12 weeks aerobic exercise. Informed consent was obtained from all participants before testing and commencing the study. In the consent, form benefits and risks involve in participation in the study explained to exercise group . Confidentially, of the information collected from the subjects was assured. It was also explained that study participant had the right to withdraw at any stage of the study. A code was allocated to each subject and at no time were names of the subject disclosure to anyone other than the researcher and assistants.

After taking positive concern of the participants, the subjects were assigned an identification number and then assisted in completing a demographic data form and Survey. Due to confidentiality concerns, no written information that identifies the individual was taken. WHOQOL Psychosocial trait questioner (WHOQOL-brief 1994) was translated from English language to Afan Oromo the local language for better 
understanding . It has 9 items which are divided into 2 domains. Each item is scored on a 5-point Likert scale from $0=$ "not at all" to $5=$ "very strong," yielding a possible range of 0 to 45 on which divided into the psychological $0-30$ subscale and 0 to 15 on the social subscale. For the current study we examined the psychology and social subscales since those parameters have been shown to provide relevant information about psychological well-being and social relationship in general, and specifically concerning HIV-1 individuals (Rojas, 2001). The WHOQOL Psychosocial trait questioner (WHOQOL-brief 1994) was given to research participants to collect the pre test data. After collecting the pretest data 12 week intervention was administrated. After intervention once again same questionair was adminstrated.

\section{Training Protocol}

Participant was attending aerobic exercise three days per week. The intensity of activity was increased 5\% every two weeks. Exercise was performed on floor and treadmill. The degree of treadmill was $0^{\circ}$ for the first six weeks and incresed $10^{\circ}$. Floor exercise was aerobic dance.

\section{Statistical Analyses of the Study}

After collecting the data the researchers used the descriptive statistics frequency counts to analyze the socio-demographic characteristics of the participants. Paired t-test and independent t-test was used to identify the significant difference between the variables of pre and post test of both control and experimental group. All analyses were executed using Statistical Package for the Social Sciences (SPSS) version 20.0 software (SPSS Inc., Chicago, Illinois, USA). $\mathrm{P}<0.05$ was considered as a significant level.

\section{Results}

\section{Demographic and socio-economic of control and exercise}

Socio-demographic Characteristics of the Participants was explened on Table -2, initial enrollment included 29 experimental and 29 control subjects total 58. 23 experimental and 20 control participants of total 43 subjects completed both pre and post evaluations of psychosocial trait. Fifteen subjects of which 6 experimental and 9 control group dropped. The preseason of drop out was due to social, financial family and health problems. Participants in the experimental group attended on average 25.44 days $\mathrm{s}$ $(70.7 \%)$ of the supervised exercise sessions. The mean monthly income of the participants were 987.3 birr where male 934.8 and female 1027.15. The mean time under ART was 3.5 years . Most participants were married ( $n=31,53.4 \%) ; 11$ ( $18 \%$ ) of them were single, 10 (17.2) of them where living as married and the rest 6 (10.3) were divorced. Most participants graduated from high school $(\mathrm{n}=23,39.6 \%)$, elementary school ( $\mathrm{n}$ $=24,41.3 \%)$, graduated from college diploma $(n=4$, $6.8 \%)$, or attended preparatory school $(n=7,12 \%)$.

Table 1

Aerobic exercise training protocol for HIV (ACSM, 2009).

\begin{tabular}{lccccc}
\hline Stages & Week & Sessions & Type of exercise & Duration (min) & Intensity \\
\hline Phase-in & $1-2$ & 6 & Aerobic & $15-20$ & $50 \%$ of HRmax \\
Step 1 & $3-4$ & 6 & Aerobic & 40 & $55 \%$ of HRmax \\
Step 2 & $5-6$ & 6 & Aerobic & 40 & $60 \%$ of HRmax \\
Step 3 & $7-8$ & 6 & Aerobic & 40 & $65 \%$ of HRmax \\
Step 4 & $9-10$ & 6 & Aerobic & 40 & $70 \%$ of HRmax \\
Step 5 & $11-12$ & 6 & Aerobic & 40 & $75 \%$ of HRmax \\
\hline
\end{tabular}


Table 2

Socio-demographic characteristics of the participants $(n=43)$.

\begin{tabular}{|c|c|c|}
\hline Characteristic & Control group & Experimental group \\
\hline Age & 34.66 & 38.1 \\
\hline \multicolumn{3}{|l|}{ Gender } \\
\hline Male & 7 & 8 \\
\hline Female & 13 & 15 \\
\hline \multicolumn{3}{|l|}{ Marital status } \\
\hline Single & 6 & 5 \\
\hline Married & 16 & 15 \\
\hline Living as married & 5 & 5 \\
\hline Divorced & 2 & 4 \\
\hline Income per month (Birr) & 979.24 & 995.44 \\
\hline No. of Year under ART & 2.6 & 2.63 \\
\hline Session & & 25.44 \\
\hline \multicolumn{3}{|l|}{ Educational level } \\
\hline None & 0 & 0 \\
\hline Elementary & 6 & 3 \\
\hline High school & 9 & 12 \\
\hline Preparatory & 4 & 5 \\
\hline Diploma & 1 & 3 \\
\hline First degree & 0 & 0 \\
\hline Second degree & 0 & 0 \\
\hline
\end{tabular}

Table 3

Independent sample t-test Baseline of psychosocial traits of both control and experimental group.

\begin{tabular}{lccccccc}
\hline Variables & Group & $\mathrm{N}$ & $\mathrm{M}$ & $\mathrm{SD}$ & $\mathrm{t}$ & $\mathrm{MD}$ & $\mathrm{p}$ \\
\hline Pre Psychological & CG & 20 & 16.25 & 1.25 & 1.76 & 0.94 & .086 \\
& EG & 23 & 15.30 & 2.09 & & & \\
\hline
\end{tabular}

Independent $t$-test on the mean baseline psychosocial profile of the control and experimental groups $P>0.05$

\section{Results of Control and Experimental Group of Psychosocial Traits}

The baseline assessment results of both experimental and control groups $(n=43)$ were assessed using the independent $t$-test for psychosocial trait of the participants in the study was presented in Table 3.

Pre-test of dependent variables was analyzed using independent $\mathrm{t}$-test. The mean difference of experimental to control was used to see intervention effects. The levels at baseline of psychosocial trait scores of the participants in the study were shown in Table 3 above. The pre test psychosocial trait mean difference score between groups was 0.94 and p-value 0.86 . Control group have been show mean score of $16.25(\mathrm{SD}=1.25)$, and the experimental group shown mean score $15.30(\mathrm{SD}=2.09)$. The outcome were proved psychosocial homogeneous at baseline . 


\section{Table 4}

Summary of paired t-test analysis comparing the baseline of mean values of psychosocial in the experimental and control groups (Mean $\pm \mathrm{SD}$ ).

\begin{tabular}{llccccccc}
\hline Variables & Group & $\mathrm{N}$ & Pre-test & Post-test & Correlation & $\mathrm{MD}$ & $\mathrm{t}$ & $\mathrm{p}$ \\
\hline \multirow{2}{*}{ Psychosocial } & Control group & 20 & $16.25 \pm 1.25$ & $16.35 \pm 2.25$ & 0.58 & 0.1 & -0.2 & 0.81 \\
& Experimental Group & 23 & $15.27 \pm 2.1$ & $35.47 \pm 4.2$ & -0.30 & 20.2 & -17.78 & $0.00^{*}$ \\
\hline
\end{tabular}

*Significant difference exists in the experimental group $(p<0.05)$

Table 5

Independent t-test of mean of psychosocial of the control and experimental groups (Mean $\pm \mathrm{SD}$ ).

\begin{tabular}{lccccc}
\hline Variables & Experimental Group & Control group & $\mathrm{MD}$ & $\mathrm{t}$ & $\mathrm{p}$ \\
\hline Post psychosocial & 35.26 & 16.35 & 18.91 & -17.76 & $0.00^{*}$ \\
\hline
\end{tabular}

*Significant difference exists in the experimental group $(p<0.05)$

Symptom improvement was noted in the exercise group on both indices. Group mean of psychosocial trait were reported in Table 4 . As compared to study pre and post test between control and experimental there was an insignificant symptom improvement of control $(\mathrm{p}=0.81, \mathrm{MD}=0.1$ ), but significantly in the experimental group in psychosocial trait $(\mathrm{p}=0.00, \mathrm{MD}=$ 20.2).

To see the effect of psychosocial trait post test was statically analyzed. Independent t-test was applied in order to see effect of intervention after 12 weeks. According to data analyzed it showed significant $(\mathrm{p}=0.00)$ and $\mathrm{MD}=18.91$.

Pre-test of dependent variables was analyzed using independent t-test. The mean difference of experimental to control was used to see intervention effects. The levels at baseline of psychosocial trait scores of the participants in the study were shown in Table 8 above. The pre test psychosocial trait mean difference score between groups was 18.91 and p-value 0.00 . Control group have been show mean score of $16.25(\mathrm{SD}=1.25)$, and the experimental group shown mean score $35.26(\mathrm{SD}=2.09)$. There is no similarity between control and experimental group.

\section{Discussion}

An ever-growing number of published studies suggest and acknowledge that exercise is the best and effective therapeutic interventions for HIV/AIDS infected people to make their living qualitatively. Notwithstanding, to the best of our knowledge, this is the first study done for Ethiopia peoples with HIV/AIDS.

The present study showed that a 12 week aerobic exercise program had positive effect on psychosocial trait of people living with HIV/AIDS (PLWHIV/AIDS). Our trial exhibited a $25.8 \%$ drop-out rate, similar to the findings of a meta-analysis on aerobic exercise and HIV/AIDS, in which studies reported drop-out rates higher than $20 \%$ and two others higher than $50 \%$ [9]. Furthermore, exercise participants achieved similar completion rates which were $70.8 \%$ to that reported for three aerobic exercise intervention trials $(70 \%, 77 \%$, and 78\% respectively) (Lox et al., 1996; Smith et al., 2001; Terry et al., 1999) and the same rate $(81 \%)$ reported by (Smith et al., 2001).

The finding in the current study aerobic exercise had a positive effect on the psychosocial trait consistent with several studies in the literature . present study, result shown that aerobic exercise had a positive effect on the psychosocial trait also consensus with the study of Hu j (Terry et al., 1999) and concluded on their study that aerobic exercise was an effective treatment for depression in older people. They mentioned that psychosocial trait such as increased self-efficacy, social interaction and reduced negative patterns may contribute to improvement in mood state. The above finding of present study also supported by others researcers that that exercise is effective as the 
treatment for psychosocial problems (Hand et al., 2009; Perna et al., 1999; Smith et al., 2001). The study conducted on effect of aerobic exercise on depression those used medication conclude that exercise group had better reductions in psychosocial problem symptoms than those who used medication those act as a control group (Sardar et al., 2004). The effects of aerobic exercise training for psychosocial symptom management in HIV-infected adults was the other study conducted (Neidig et al., 2003). A study of sixmonth, supervised, aerobic and resistance exercise program improves self-efficacy in people with human immunodeficiency virus a randomized controlled trial was reported improvements in depressive symptoms and depressed mood as compared to a control group didn't show change (Fillipas et al., 2006).

\section{Conclusion}

It was concluded that the three-month, supervised, and moderate aerobic exercise program, performed three times a week, can improve the psychosocial traits. Aerobic exercise has a positive effect on psychosocial trait in people living with HIV/AIDS when it combines with ART rather than ART alone. Aerobic exercise is a safe, complimentary method to manage HIV symptoms, and in this manner enhances of either psychological or social well being (Fillipas et al., 2006). Given the promising results of this study, future trials should focus more upon longer duration exercise programs for enhancing the general health status of individuals infected with HIV.

\section{References}

ACSM. ACSM's exercise management for persons with chronic diseases and disabilities. Human Kinetics, Champaign, IL, 2009.

Agin D, Gallagher D, Wang J, Heymsfield SB, Pierson RN Jr, Kotler DP. Effects of whey protein and resistance exercise on body cell mass, muscle strength, and quality of life in women with HIV. AIDS, 2001; 15: 2431-2440.

Anandh V, Peter I, Alagesan J, K Rajendran. Effect of progressive resistance training on functional capacity, quality of life and $\mathrm{cd} 4$ count in people with hiv/aids. Int J Physiother Res, 2014; 2(4): 626-630.

Ayàn C, Martin V, Alonso-Cortes A, Alvarez MJ, Valencia M, Barientos MJ. Relationship between aerobic fitness and QOL in female fibromyalgia patients. Clinical Rehabilitation, 2007; 21: 1109-1113.

Bhasin S, Storer TW, Javanbakht M, Berman N, Yarasheski KE, Phillips J, Dike M, Sinha-Hikim I, Shen R, Hays $\mathrm{RD}$, Beall G. Testosterone replacement and resistance exercise in HIV-infected men with weight loss and low testosterone levels. JAMA, 2000; 283: 763-770.

Cunningham WE, Hays RD, Duan N, Andersen R, Nakazono TT, Bozzette SA. Shapiro MF. The effect of socioeconomic status on the survival of people receiving care for HIV infection in the United States. J Health Care PoorUnderserved, 2005; 16: 655-676.

Eller LS. Quality of life in persons living with HIV. Clinical Nursing Research, 2001; 10(4): 401-423.

Fairfield WP, Treat M, Rosenthal DI, Frontera W, Stanley T, Corcoran C. Costello M, Parlman K, Schoenfeld D, Klibanski A, Grinspoon S. Effects of testosterone and exercise on muscle leanness in eugonadal men with AIDS wasting. J Appl Physiol, 2001; 90: 2166-2171

Fillipas S, Oldmeadow LB, Bailey MJ, Cherry CL. A sixmonth, supervised, aerobic and resistance exercise program improves self-efficacy in people with human immunodeficiency virus: a randomized controlled trial. Australian Journal of Physiother, 2006; 52(3): $185-90$

Hand GA, Lyerly GW, Jaggers JR, Dudgeon WD. Impact of aerobic and resistance exercise on the health of HIVinfected persons. American Journal of Lifestyle Medicine, 2009; 3(6): 489-499.

Hays RD, Cunningham WE, Sherbourne CD, Wilson IB, WU AW, Cleary PD, McCaffrey DF, Fleishman JA, Crystal S, Collins R, Eggan F, Shapiro MF, Bozette SA. Healthrelated quality of life in patients with human immunodeficiency $\backslash$ cy virus infection in the United States: results from the HIV cost and services utilization study. Am J Med, 2000; 108(9): 714-722.

$\mathrm{Hu} \mathrm{J}$, Gruber KJ. Positive and negative affect and health functioning indicators among older adults with chronic illnesses. Issues Ment Heathens, 2008; 29(8): 895-911.

LaPerriere AR, Antoni MH, Schneiderman N, Ironson G, Klimas N, Caralis P, Fletcher MA. Exercise Intervention Attenuates Emotional Distress and Natural Killer Cell Decrements Following Notification of Positive Serologic Status for HIV-1. Biofeedback Self Regul, 1990; 15: 229-242.

Lox CL, McAuley E, Tucker RS. Aerobic and resistance exercise training effects on body composition, 
muscular strength, and cardiovascular fitness in an HIV-1 population. Int J Behav Med, 1996; 3: 55-69.

Mutimura E, Stewart A, Crowther NJ, Yarasheski KE, Cade WT. The effects of exercise training on quality of life in HAART-treated HIV-positive Rwandan subjects with body fat redistribution. Qual Life Res, 2008; 17: 377-385.

Neidig J, Smith B, Brashers DE. Aerobic exercise training for depressive symptom management in adults living with HIV infection. Journal of the Association of Nurses in AIDS Care, 2003; 14(2): 30-40.

O'Brien K, Nixon S, Tynan AM, Glazier R. Aerobic exercise interventions for adults living with HIV/AIDS. Cochrane Database Syst Rev, 2010; 4: CD001796.

Ortiz A. Exercise for adults living with human immunodeficiency virus infection in the era of highly active antiretroviral therapy. Int J Phys Med Rehabil, 2014; 2: 213. doi:10.4172/2329-9096.1000213

Pais-Ribeiro J, Ponte AC. Propriedades métricas da versão portuguesa daescala de suporte social do MOS (MOS Social Support Survey) com idosos. Psicologia, Saúde \& Doenças, 2009; 10(2): 163-174.

Perna FM, LaPerriere A, Klimas N, Ironson G, Perry A, Pavone J, Goldstein A, Majors P, Makemson D, Talutto C, Schneiderman N, Fletcher MA, Meijer OG, Koppes L. Cardiopulmonary and CD4 cell changes in response to exercise training in early symptomatic HIV infection. MED Sci Sports Exerc, 1999; 31(7): 973979.

Roubenhof FR, Weis L, McDermott A, Heflin T, Cloutier GJ, Wood M, Gorbach S. A pilot study of exercise training to reduce tranquil fat in adults with HIV-associated fat redistribution. AIDS, 1999; 13: 1373-1375.

Sardar MA, Boghrabadi V, Sohrabi M, Aminzadeh R, Jalalian $M$. The effects of aerobic exercise training on psychosocial aspects of men with type 2 diabetes mellitus. Global Journal of Health Science, 2014; 6(2): 196-202. http://dx.doi.org/10.5539/gjhs.v6n2p196

Smith BA, Neidig JL, Nickel JT, Mitchell GL, Para MF, Fass RJ. Aerobic exercise: effects on parameters related to fatigue, dyspnea, weight and body composition in HIV-infected adults. AIDS, 2001; 15: 693-701.

Stringer WW, Berezovskaya M, O'Brien WA, Beck CK, Casaburi R. The effect of exercise training on aerobic fitness, immune indices, and quality of life in HIV+ patients. MED Sci Sports Exerc, 1998; 30: 11-16.

Terry L, Sprinz E, Ribeiro JP. Moderate and high intensity exercise training in HIV-1 seropositive individuals: a randomized trial. Int J Sports Med, 1999; 20: 142-146.

The WHOQOL Group. The development of the World Health Organization quality of life assessment instrument (the WHOQOL). In J. Orley and W. Kuyken (Eds) Quality of Life Assessment: International Perspectives. Heidelberg: Springer Verlag, 1994.

Webb A. Clinical assessment of symptom-focused healthrelated quality of life in HIV/AIDS. Journal of the Association of Nurses in AIDS Care, 2004; 15(2): 6781.

Yang J, Li SJ, Zheng YL. Predictors of depression in Chinese communitydwelling people with type 2 diabetes. J Clin Nurs, 2009; 18(9): 1295-1304. 